\title{
PANCREAS
}

\section{Cigarette smoking accelerates progression of alcoholic chronic pancreatitis}

\author{
P Maisonneuve, A B Lowenfels, B Müllhaupt, G Cavallini, P G Lankisch, J R Andersen, \\ E P DiMagno, A Andrén-Sandberg, L Domellöf, L Frulloni, R W Ammann
}

Gut 2005;54:510-514. doi: 10.1136/gut.2004.039263

See end of article for authors' affiliations

......................

Correspondence to: Dr P Maisonneuve, Epidemiology Unit, European Institute of Oncology, Via Ripamonti 435, 20141 Milan, Italy; patrick.maisonneuve@ ieo.it

Revised version received 26 May 2004

Accepted for publication 1 June 2004
Background: Smoking is a recognised risk factor for pancreatic cancer and has been associated with chronic pancreatitis and also with type II diabetes.

Aims: The aim of this study was to investigate the effect of tobacco on the age of diagnosis of pancreatitis and progression of disease, as measured by the appearance of calcification and diabetes.

Patients: We used data from a retrospective cohort of 934 patients with chronic alcoholic pancreatitis where information on smoking was available, who were diagnosed and followed in clinical centres in five countries.

Methods: We compared age at diagnosis of pancreatitis in smokers versus non-smokers, and used the Cox proportional hazards model to evaluate the effects of tobacco on the development of calcification and diabetes, after adjustment for age, sex, centre, and alcohol consumption.

Results: The diagnosis of pancreatitis was made, on average, 4.7 years earlier in smokers than in nonsmokers $(p=0.001)$. Tobacco smoking increased significantly the risk of pancreatic calcifications (hazard ratio (HR) 4.9 (95\% confidence interval (CI) 2.3-10.5) for smokers $v$ non-smokers) and to a lesser extent the risk of diabetes (HR $2.3(95 \% \mathrm{Cl} 1.2-4.2))$ during the course of pancreatitis.

Conclusions: In this study, tobacco smoking was associated with earlier diagnosis of chronic alcoholic pancreatitis and with the appearance of calcifications and diabetes, independent of alcohol consumption.
$\mathrm{A}$ lthough alcohol is recognised as the major cause of chronic pancreatitis, smoking has been described as an additional risk factor. ${ }^{12}$ Calcification, pancreatic insufficiency, and diabetes are common in chronic pancreatitis but little is known of the promoting role of smoking on the evolution of these complications. Using data from a retrospective cohort study originally designed to evaluate the risk of pancreatic cancer in patients with chronic pancreatitis, ${ }^{3}$ we have now investigated the role of tobacco on progression of alcoholic pancreatitis, as measured by age at diagnosis of disease and time until appearance of calcification and diabetes.

\section{METHODS}

In this report, we selected from our original historical cohort $(n=1552)$ those patients with alcoholic chronic pancreatitis for whom smoking status was known. We also obtained updated data from Switzerland. The final study population consisted of 934 patients with chronic alcoholic pancreatitis for whom data were retrieved from clinical records or existing computerised databases in clinical centres specialising in the management of chronic pancreatitis. The number of cases from each country was as follows: Switzerland, 239; Germany, 140; USA, 202; Italy, 315; and Sweden, 38. Centre specific clinical details, methods of diagnosis, and treatment of pancreatitis have been described in previous publications. ${ }^{4-9}$ The diagnosis was based on a combination of the following criteria: symptoms of chronic epigastric pain, steatorrhoea, or both; radiographic evidence of pancreatic calcification; evidence of chronic pancreatitis on histological or pancreatographic procedures; and results of laboratory tests (that is, exocrine insufficiency). Determination of the two end points of the study-pancreatic calcification or diabetes-was measured by the presence of calcification on abdominal radiography or by an elevated fasting blood sugar or an abnormal glucose tolerance test.
The cohort from which this series of patient derived has already been studied to evaluate the risk of pancreatic cancer in those with chronic pancreatitis and to determine which factors predict mortality. ${ }^{30}$ The database included information on demographic and clinical characteristics of the patients, including the presence and date of diagnosis of calcification and/or diabetes, as well as information on smoking status and level of alcohol consumption recorded at the onset of disease. Alcohol consumption, when available, was categorised as low to moderate $(<5$ alcoholic drinks/ day), heavy (5-9 drinks/day), or very heavy (10 or more drinks/day).

Student's $t$ tests were used to compare age at diagnosis of pancreatitis in smokers versus non-smokers. We used logistic regression analysis to evaluate the association between tobacco and the presence of calcification or diabetes either at the time of diagnosis of chronic alcoholic pancreatitis or at the end of the follow up period. Cox proportional hazards regression analysis was used to evaluate the promoting role of tobacco on the time to development of calcification or diabetes after the initial diagnosis of chronic pancreatitis. All models were adjusted for age, sex, centre, and alcohol consumption ( $\geqslant 5 v<5$ drinks/day). Plots of the cumulative incidence of calcification and diabetes after the diagnosis of pancreatitis were drawn using the Kaplan Meier method. The log rank test was used to compare the incidence of calcification and/or diabetes between smokers and non-smokers. Because either calcification or diabetes may precede the diagnosis of chronic pancreatitis, we also plotted the cumulative incidence of calcification and diabetes starting from birth. Before presenting the results from the log rank tests or from the Cox models, we tested the proportional hazard assumption by introducing a constructed time dependent variable and testing for its significance. Data were analysed using SAS procedures; all tests were two sided. 
Table 1 Characteristics of 934 patients with chronic alcoholic pancreatitis

\begin{tabular}{|c|c|c|c|c|c|c|c|c|}
\hline & \multirow[b]{2}{*}{$\begin{array}{l}\text { No of } \\
\text { patients }\end{array}$} & \multirow[b]{2}{*}{$\begin{array}{l}\text { Mean age } \\
\text { at } \mathrm{Dx}^{*}(y)\end{array}$} & \multicolumn{3}{|l|}{ Calcification } & \multicolumn{3}{|l|}{ Diabetes } \\
\hline & & & At diagnosis $†$ & $\begin{array}{l}\text { During } \\
\text { follow up }\end{array}$ & $\begin{array}{l}\text { At any } \\
\text { time } \S\end{array}$ & At diagnosis $†$ & $\begin{array}{l}\text { During } \\
\text { follow upł }\end{array}$ & $\begin{array}{l}\text { At any } \\
\text { time§ }\end{array}$ \\
\hline All subjects & 934 & 45.0 & 370 & 258 & 673 & 198 & 273 & 481 \\
\hline \multicolumn{9}{|c|}{ Alcohol drinking status at onset of chronic pancreatitis } \\
\hline Moderate drinkers & 159 & 50.1 & 43 & 39 & 88 & 25 & 32 & 59 \\
\hline Heavy drinkers & 314 & 46.1 & 111 & 87 & 223 & 63 & 72 & 139 \\
\hline Very heavy drinkers & 205 & 41.0 & 66 & 68 & 147 & 56 & 57 & 16 \\
\hline Quantity unknown & 256 & 43.4 & 150 & 64 & 215 & 54 & 112 & 167 \\
\hline \multicolumn{9}{|c|}{ Smoking status at onset of chronic pancreatitis } \\
\hline Never smokers & 64 & 49.3 & 15 & 7 & 29 & 17 & 11 & 29 \\
\hline Ever smokers & 870 & 44.6 & 355 & 251 & 644 & 181 & 262 & 452 \\
\hline$<1$ pack cig./day & 130 & 43.0 & 51 & 37 & 95 & 33 & 35 & 70 \\
\hline$>1$ pack cig./day & 553 & 42.5 & 243 & 166 & 436 & 119 & 208 & 332 \\
\hline Amount unknown & 187 & 52.2 & 61 & 48 & 113 & 29 & 19 & 50 \\
\hline \multicolumn{9}{|c|}{$\begin{array}{l}\text { Dates for calcification or diabetes were missing for a few subjects. } \\
\text { *Mean age at diagnosis of chronic pancreatitis. } \\
\text { †Number of patients with condition present at diagnosis. } \\
\text { †Number of patients who developed the condition during follow up. } \\
\text { \$Number of patients with condition present at any time. } \\
\text { - Subjects are stratified as moderate drinkers if drinking less than } 5 \text { drinks/day, heavy drinkers if drinking 5-9 drinks/day, or very heavy drinkers if drinking } 10 \text { or } \\
\text { more drinks/day. }\end{array}$} \\
\hline
\end{tabular}

\section{RESULTS}

The cohort comprised 934 patients (814 males, 120 females) with a confirmed diagnosis of chronic alcoholic pancreatitis and available smoking information. Ninety three per cent of males and $91 \%$ of females ever smoked. Duration of follow up was 8.4 (SD 7.6) years. There was no difference in duration of follow up for smokers and non-smokers $(p=0.48)$.

Overall, smokers were diagnosed with pancreatitis at a younger age (mean 44.6 (SD 10.9) years) than non-smokers (mean 49.3 ( 14.3$)$ years) $(\mathrm{p}=0.001)$. The majority of patients were heavy or very heavy ( $\geqslant 5$ drinks/day) alcohol drinkers (65\% of non-smokers $v 77 \%$ of smokers; $p=0.06)$.

Calcification was present at the time of diagnosis of pancreatitis in $40 \%$ of males and in $34 \%$ of females. It was subsequently detected in $28 \%$ of males and $38 \%$ of females during a mean follow up period of 8.4 years. In addition, calcification was mentioned but the date of development was unknown for $6.1 \%$ of males and $5.8 \%$ of females. Similarly, diabetes was present at diagnosis of pancreatitis in $21 \%$ of males and $20 \%$ of females and developed during follow up in $30 \%$ of males and $27 \%$ of females (table 1 ).

Smoking was associated with a higher prevalence of calcification at the time of diagnosis of pancreatitis (odds ratio (OR) 2.0 (95\% confidence interval (CI) 1.1-3.8)) but was not related to the prevalence of diabetes (OR 0.9 (95\% CI $0.5-1.7)$ ) (table 2).
Development of calcification after the initial diagnosis of pancreatitis was significantly associated with cigarette smoking (hazards ratio (HR) 4.9 (95\% CI 2.3-10.5)) (table 2). The risk was similar for moderate $(<1$ pack cig./day) and heavy $(>1$ pack cig./day) smokers. Figure 1 illustrates the cumulative incidence of calcification and diabetes according to smoking status in patients with chronic alcoholic pancreatitis. Two starting points (birth and diagnosis of chronic pancreatitis) were considered. By age 60 years, $80 \%$ of smokers had signs of calcification compared with $40 \%$ of nonsmokers. Smoking was also associated with a significant increase in the risk of developing diabetes after the diagnosis of pancreatitis (HR 2.3 (95\% CI 1.2-4.2)) (table 2).

For $80 \%$ of smokers, quantitative information on daily tobacco consumption was available. The magnitude of the association between smoking and calcification or diabetes was similar for patients who smoked $<1$ pack/day and those who smoked $>1$ pack/day (table 2). Surprisingly, patients classified as smokers but with missing quantitative data were diagnosed at an older age than ever smokers (table 2). Nearly all patients (93\%) with missing quantitative data were from the US centre where we previously reported that age at diagnosis of pancreatitis was approximately 10 years older than in other centres. ${ }^{3}$ Nevertheless, even in the USA, mean age at diagnosis of pancreatitis was older for never smokers (59.4 years) than for ever smokers (52.5 years).

Table 2 Risk of calcification and diabetes in relation to cigarette smoking

\begin{tabular}{llll}
\hline & $\begin{array}{l}\text { At diagnosis of CP } \\
\text { OR }(95 \% \text { CI) }\end{array}$ & $\begin{array}{l}\text { During follow up } \\
\text { HR }(95 \% \text { CI) }\end{array}$ & $\begin{array}{l}\text { At any time } \\
\text { OR (95\% CI) }\end{array}$ \\
\hline Calcifications & 1.0 & 1.0 & 1.0 \\
$\quad$ Non-smokers & $2.0(1.1-3.8)$ & $4.9(2.3-10.5)$ & $2.8(1.5-5.0)$ \\
Smokers & $2.5(1.2-5.3)$ & $4.2(1.8-9.7)$ & $3.3(1.7-6.7)$ \\
$<1$ pack cig./day & $2.1(1.1-4.2)$ & $4.2(1.9-9.2)$ & $3.5(1.9-6.3)$ \\
>1 pack cig./day & $1.6(0.7-3.8)$ & $6.8(2.9-16.0)$ & $2.5(1.1-5.4)$ \\
$\quad$ Amount unknown & 1.0 & 1.0 & 1.0 \\
Diabetes & $0.9(0.5-1.7)$ & $2.3(1.2-4.2)$ & $1.5(0.8-2.8)$ \\
$\quad$ Non-smokers & $1.0(0.4-2.2)$ & $2.0(1.0-4.2)$ & $1.3(0.7-2.6)$ \\
Smokers & $0.8(0.4-1.6)$ & $2.1(1.1-3.9)$ & $1.5(0.8-2.7)$ \\
$<1$ pack cig./day & $1.3(0.5-3.6)$ & $3.1(1.4-7.0)$ & $2.7(1.0-7.5)$ \\
>1 pack cig./day & &
\end{tabular}

$\mathrm{CP}$, chronic pancreatitis; $\mathrm{OR}$, odds ratio; $\mathrm{HR}$, hazards ratio; $\mathrm{Cl}$, confidence interval.

Estimates were adjusted for age, sex, centre, and alcohol consumption $(\geqslant 5 /<5$ drinks/day). 

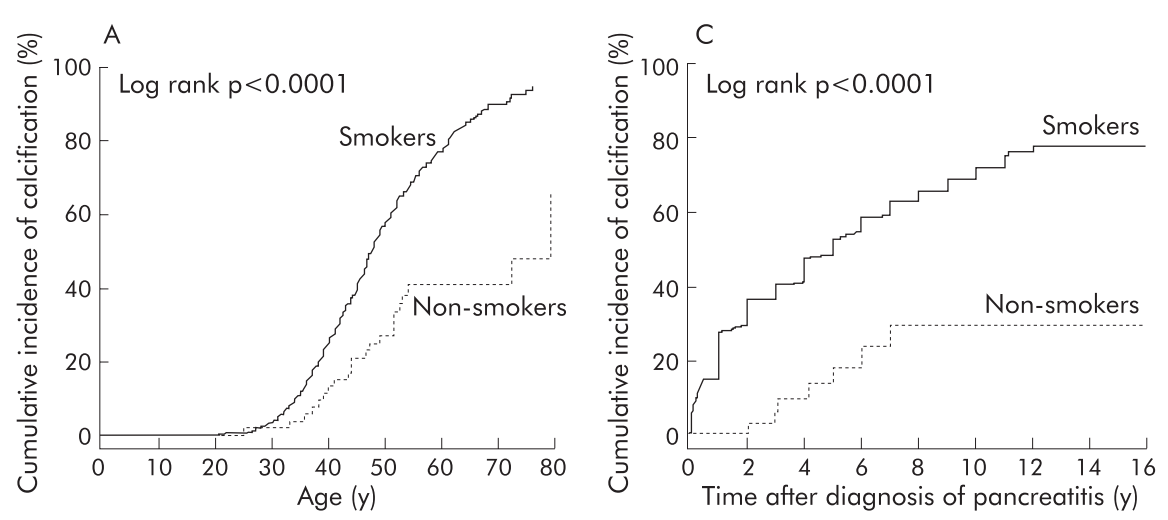

Figure 1 Cumulative incidence of calcification (A) and diabetes (B) since birth in smokers and non-smokers in chronic alcoholic pancreatitis, and cumulative incidence of calcification (C) and diabetes (D) developing after the diagnosis of chronic alcoholic pancreatitis.
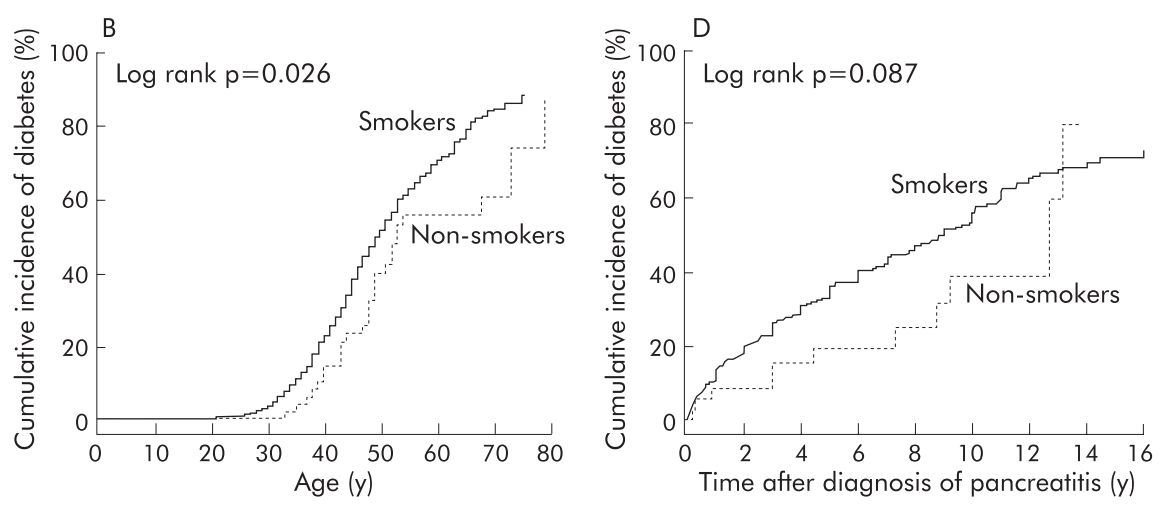

Subjects at risk

$\begin{array}{lrrrrrrrr}\text { Smokers } & 56 & 56 & 53 & 46 & 35 & 14 & 10 & 1 \\ \text { Non-smokers } & 821 & 820 & 788 & 587 & 284 & 108 & 20 & 2\end{array}$

$\begin{array}{rrrrrrrrr}466 & 255 & 195 & 120 & 83 & 52 & 28 & 12 & 5 \\ 41 & 33 & 24 & 13 & 10 & 8 & 5 & 1 & 1\end{array}$

In order to limit the possibility of residual confounding due to alcohol, we performed a stratified analysis based on three different levels of alcohol consumption: the magnitude of the associations reported previously were similar in all groups (table 3).

The results were homogeneous within countries although the number of non-smokers in each single country was limited, and country specific risk estimates had large confidence intervals. In particular, the risk of developing calcification after the initial diagnosis of chronic alcoholic pancreatitis was HR $=4.1(1.7-10.1)$ for non-US subjects and HR $=5.1(1.2-21.5)$ for US subjects who were diagnosed with chronic pancreatitis at an older age. Finally, as some of the
Italian data in this study were reported previously, ${ }^{1}$ we performed an additional analysis after excluding this centre. The findings remained unchanged but became stronger.

\section{DISCUSSION}

From our previous analysis of this data set, we reported that age at diagnosis, smoking, and drinking were major independent predictors of mortality in patients with chronic pancreatitis ${ }^{10}$ but the mechanisms or the intermediate effects were not described.

Tobacco has been described as an important risk factor for chronic pancreatitis and is the strongest known environmental risk factor for pancreatic cancer. ${ }^{1}$ Patients with

Table 3 Risk of calcification and diabetes in relation to cigarette smoking for various levels of alcohol consumption assessed at the time of diagnosis of chronic pancreatitis

\begin{tabular}{|c|c|c|c|}
\hline Strata & $\begin{array}{l}\text { At diagnosis of CP } \\
\text { OR }(95 \% \mathrm{CI}) \\
\text { for smokers } \mathrm{v} \\
\text { non-smokers }\end{array}$ & $\begin{array}{l}\text { During follow up } \\
\text { HR }(95 \% \mathrm{Cl}) \\
\text { for smokers } v \\
\text { non-smokers }\end{array}$ & $\begin{array}{l}\text { At any time } \\
\text { OR }(95 \% \mathrm{Cl}) \\
\text { for smokers } v \\
\text { non-smokers }\end{array}$ \\
\hline \multicolumn{4}{|l|}{ Calcifications } \\
\hline All subjects & $2.0(1.1-3.8)$ & $4.9(2.3-10.5)$ & $2.8(1.5-5.0)$ \\
\hline Moderate drinkers* & $3.1(0.7-14.9)$ & $4.2(1.0-17.6)$ & $3.8(1.2-12.0)$ \\
\hline Heary drinkers* & $1.9(0.7-5.8)$ & $3.0(1.2-7.6)$ & $1.5(0.6-3.8)$ \\
\hline Very heavy drinkers* & $2.1(0.4-10.7)$ & NA & $7.9(1.9-33.1)$ \\
\hline \multicolumn{4}{|l|}{ Diabetes } \\
\hline All subjects & $0.9(0.5-1.7)$ & $2.3(1.2-4.2)$ & $1.5(0.8-2.8)$ \\
\hline Moderate drinkers* & $2.4(0.4-13.4)$ & $2.1(0.6-6.8)$ & $1.8(0.5-7.2)$ \\
\hline Heavy drinkers* ${ }^{*}$ & $1.0(0.3-3.1)$ & $3.0(0.9-9.8)$ & $2.0(0.7-5.9)$ \\
\hline Very heavy drinkers* & $2.9(0.5-15.1)$ & $2.6(0.6-11.0)$ & $4.3(1.1-17.4)$ \\
\hline
\end{tabular}

$\mathrm{CP}$, chronic pancreatitis; $\mathrm{OR}$, odds ratio; $\mathrm{HR}$, hazards ratio; $\mathrm{Cl}$, confidence interval; $\mathrm{NA}$, not available. Estimates were adjusted for age, sex, and centre.

*Subjects are stratified as moderate drinkers if drinking less than 5 drinks/day, heavy drinkers if drinking 5-9 drinks/day, or very heavy drinkers if drinking 10 or more drinks/day. 
chronic pancreatitis are at high risk of developing pancreatic cancer but whether this is a true association or the result of confounding by smoking has been controversial. ${ }^{11}{ }^{12}$ It has recently been reported that smoking accelerates the onset of pancreatic cancer in high risk groups. ${ }^{13}{ }^{14}$

In the present large multicentre study, we have shown that smoking contributes to deterioration of pancreatitis, as measured by the appearance of calcification and diabetes, confirming previous reports. Initially, in 1994, Cavallini et al first described the effect of tobacco and alcohol on pancreatic lithogenesis in the course of chronic pancreatitis. They found that medium to heavy smokers had a significantly increased risk of developing calcifications but found no effects of alcohol. ${ }^{15}$ Imoto and DiMagno also found that cigarette smoking increased the risk of pancreatic calcification in late onset idiopathic chronic pancreatitis in those who never consumed alcoholic beverages, providing further evidence of the independent effect of smoking on the development of calcification. ${ }^{16}$ In our study, adjustment for alcohol consumption or stratification for different levels of alcohol consumption (moderate, heavy, very heavy) did not change the results. Smoking is also responsible for calcification in many other organs. In particular, it is strongly associated with coronary artery and aortic arch calcification ${ }^{17} 18$ and with placental calcification. ${ }^{19} 20$

The mechanism by which smoking contributes to pancreatic injury or by which smoking accelerates the pancreatic inflammatory process is still unknown but laboratory studies have found that activation of multiple signal transduction pathways due to nicotine exposure results in high levels of intracellular calcium release and may be responsible for cell cytotoxicity and cell injury. ${ }^{21}$

Little has been published on the association between calcification and pancreatic cancer, unlike its association with diabetes which has long been noted. The nature of this association and whether diabetes is a true aetiological risk factor for pancreatic cancer or solely associated with the development of the tumour remain unclear. Heavy smoking, which has been identified as a risk factor for non-insulin dependent diabetes mellitus in several studies, ${ }^{22-24}$ could in part act as a confounder in the relation between longstanding diabetes and pancreatic cancer. ${ }^{25}$ This is supported by our study which showed that smoking enhanced the development of diabetes in patients with chronic pancreatitis, with a risk of the same magnitude as that for developing pancreatic cancer in long term diabetics. Cigarette smoking has also been associated with abnormal fasting glucose levels ${ }^{26}$ while light to moderate alcohol consumption has been associated with a decreased risk of developing type 2 diabetes mellitus. ${ }^{27}{ }^{28}$ However, the mechanism by which cigarette smoking increases the risk of impaired fasting glucose and type 2 diabetes remains unclear. Laboratory studies have indicated that cigarette smoking may cause insulin resistance in peripheral tissues. ${ }^{29}$ In an experimental control trial using two oral glucose tolerance tests, smoking acutely impaired glucose tolerance and acutely increased serum insulin and C peptide levels. ${ }^{30}$ In addition, levels of counterregulatory hormones to insulin, such as catecholamines, increased by substances in cigarettes, may lead to insulin resistance. ${ }^{31}$

The epidemiological evidence linking smoking and pancreatic damage is further supported by pathology reports and recent advances in molecular biology. In 1986, Auerbach and Garfinkel identified histological changes in the pancreas in relation to smoking and coffee drinking habits. ${ }^{32}$ Since then, development of new molecular technology has allowed identification of the k-ras oncogene which is mutated in over $90 \%$ of pancreatic cancers. It is generally accepted that ras mutations are a frequent ${ }^{33}$ early event in the pathogenesis of a variety of neoplastic and non-neoplastic pancreatic lesions. Furthermore, k-ras mutations are about the only molecular alteration found in chronic pancreatitis and in those ductal hyperplasias known to bear the highest malignant potential. ${ }^{34} 35$

Recently, the appearance of k-ras mutations in benign and malignant pancreatic diseases has been associated with tobacco. ${ }^{36-38}$ In particular, Malats et al found high rates of $\mathrm{k}$-ras mutations in patients with exocrine pancreatic cancer who only smoked and in patients who only drank. ${ }^{36}$ Berger et al confirmed the association with smoking using nonneoplastic pancreata from individuals who smoked more than two packs of cigarettes/day for 20 or more years. ${ }^{37}$

We recognise the limitations of our study. In particular, information on smoking and drinking was from patient clinical records or from existing computerised databases, and were not collected prospectively and in a standardised fashion directly from the patient. As a result, these data were missing or incomplete for a large number of patients from the original cohort, which weaken the study results. Also, detailed information on age of onset and duration of smoking and drinking was not available, and hence there is potential for residual confounding of smoking behaviour by drinking behaviour, especially if smokers started drinking earlier than non-smokers.

In conclusion, we found that exposure to tobacco smoking was associated with an earlier diagnosis of chronic alcoholic pancreatitis (by approximately five years) and predisposed to the development of both calcification and diabetes. Further epidemiological studies using newer biomolecular techniques should provide new insights into the pathogenesis of benign and malignant pancreatic diseases.

\section{ACKNOWLEDGEMENTS}

This study was supported by grants from the CD Smithers Foundation, Solvay Pharmaceuticals Corporation, A Waring Foundation Zurich, and the Italian Association for Cancer Research (AIRC).

\section{Authors' affiliations}

P Maisonneuve, Division of Epidemiology and Biostatistics, European Institute of Oncology, Milan, Italy

A B Lowenfels, Departments of Surgery and Community and Preventive Medicine, New York Medical College, Valhalla NY, USA

B Müllhaupt, R W Ammann, Gastroenterology Service, Department of Medicine, University Hospital, Zurich, Switzerland

G Cavallini, L Frulloni, Department of Surgical and Gastroenterological Sciences, University of Verona, Italy

P G Lankisch, Department of Internal Medicine, Municipal Clinic, Lüneburg, Germany

J R Andersen, Department of Gastroenterology, Hvidovre Hospital, University of Copenhagen, Denmark

E P DiMagno, Gastrointestinal Research Unit, Mayo Clinic, Rochester, $M N$, USA

Å Andrén-Sandberg, Department of Surgery, Lund University, Sweden L Domellöf, Department of Surgery, University Hospital Örebro, Sweden

Conflict of interest: None declared.

\section{REFERENCES}

1 Talamini G, Bassi C, Falconi M, et al. Alcohol and smoking as risk factors in chronic pancreatitis and pancreatic cancer. Dig Dis Sci 1999;44:1303-11.

2 Chowdhury P, Rayford PL. Smoking and pancreatic disorders. Eur J Gastroenterol Hepatol 2000; 12:869-77.

3 Lowenfels AB, Maisonneuve P, Cavallini G, et al. Pancreatitis and the risk of pancreatic cancer. N Engl J Med 1993;328:1433-7.

4 Ammann RW, Akovbiantz A, Largiader F, et al. Course and outcome of chronic pancreatitis. Longitudinal study of a mixed medical-surgical series of 245 patients. Gastroenterology 1984;86:820-8.

5 Ammann RW, Muellhaupt B. The natural history of pain in alcoholic chronic pancreatitis. Gastroenterology 1999;116:1132-40.

6 Cavallini G, Frulloni L, Pederzoli P, et al. Long-term follow-up of patients with chronic pancreatitis in Italy. Scand J Gastroenterol 1998;33:880-9.

7 Copenhagen Pancreatitis Study. An interim report from a prospective epidemiological multicentre study. Scand J Gastroenterol 1981;16:305-12. 
8 DiMagno EP. Early diagnosis of chronic pancreatitis and pancreatic cancer Med Clin North Am 1988;72:979-92.

9 Lankisch PG, Löhr-Happe A, Otto J, et al. Natural course in chronic pancreatitis. Digestion 1993:54:148-55.

10 Lowenfels AB, Maisonneuve P, Cavallini G, et al. Prognosis of chronic pancreatitis: An international multicenter study. Am J Gastroenterol 1994;89:1467-71

11 Karlson BM, Ekbom A, Josefsson S, et al. The risk of pancreatic cancer following pancreatitis: an association due to confounding? Gastroenterology 1997; 1 13:587-92.

12 Lowenfels AB, Maisonneuve P. Pancreatic disease: Does "itis" lead to "oma"? Gastroenterology 1998;114:859-60.

13 Lowenfels AB, Maisonneuve $P$, Whitcomb DC, et al. Cigarette smoking as a risk factor for pancreatic cancer in patients with hereditary pancreatitis. JAMA 2001;286:169-70

14 Rulyak SJ, Lowenfels AB, Maisonneuve P, et al. Risk factors for the development of pancreatic cancer in familial pancreatic cancer kindreds. Gastroenterology 2003;124:1292-9.

15 Cavallini G, Talamini G, Vaona B, et al. Effect of alcohol and smoking on pancreatic lithogenesis in the course of chronic pancreatitis. Pancreas 1994;9:42-6

16 Imoto M, DiMagno EP. Cigarette smoking increases the risk of pancreatic calcification in late-onset but not in early-onset idiopathic chronic pancreatitis. Pancreas 2000;21:115-19.

17 Newman AB, Naydeck BL, Sutton-Tyrrell K, et al. Coronary artery calcification in older adults to age 99: prevalence and risk factors. Circulation 2001; 104:2679-84.

18 Iribarren C, Sidney S, Sternfeld B, et al. Calcification of the aortic arch: risk factors and association with coronary heart disease, stroke, and peripheral vascular disease. JAMA 2000;283:2810-15.

19 Klesges LM, Murray DM, Brown JE, et al. Relations of cigarette smoking and dietary antioxidants with placental calcification. Am J Epidemiol 1998; 147:127-35

20 Brown HL, Miller JM Jr, Khawli O, et al. Premature placental calcification in maternal cigarette smokers. Obstet Gynecol 1988;71:914-17.

21 Chowdhury P, MacLeod S, Udupa KB, et al. Pathophysiological effects of nicotine on the pancreas: An update. Exp Biol Med 2002:227:445-54.

22 Rimm EB, Manson JE, Stampfer MJ, et al. Cigarette smoking and the risk of diabetes in women. Am J Public Health 1993;83:211-14.

23 Rimm EB, Chan J, Stampfer MJ, et al. Prospective study of cigarette smoking, alcohol use, and the risk of diabetes in men. BMJ 1995;310:555-9.
24 Manson JE, Ajani UA, Liu S, et al. A prospective study of cigarette smoking and the incidence of diabetes mellitus among US male physicians. Am J Med 2000;109:538-42.

25 Everhart J, Wright D. Diabetes mellitus as a risk factor for pancreatic cancer. JAMA 1995;273:1605-9.

26 Nakanishi N, Nakamura K, Matsuo Y, et al. Cigarette smoking and risk for impaired fasting glucose and type 2 diabetes in middle-aged Japanese men. Ann Intern Med 2000;133:183-91.

27 Ajani UA, Hennekens $\mathrm{CH}$, Spelsberg A, et al. Alcohol consumption and risk of type 2 diabetes mellitus among US male physicians. Arch Intern Med 2000;160:1025-30.

28 Nakanishi N, Suzuki K, Tatara K. Alcohol consumption and risk for development of impaired fasting glucose or type 2 diabetes in middle-aged Japanese men. Diabetes Care 2003;26:48-54.

29 Facchini FS, Hollenbeck CB, Jeppesen J, et al. Insulin resistance and cigarette smoking. Lancet 1992;339:1 128-30.

30 Frati AC, Iniestra F, Ariza CR. Acute effect of cigarette smoking on glucose tolerance and other cardiovascular risk factors. Diabetes Care 1996;19:112-18.

31 Cryer PE, Haymond MW, Santiago JV, et al. Norepinephrine and epinephrine release and adrenergic mediation of smoking-associated hemodynamic and metabolic events. N Engl J Med 1976;295:573-7.

32 Auerbach O, Garfinkel L. Histologic changes in pancreas in relation to smoking and coffee-drinking habits. Dig Dis Sci 1986;31:1014-20.

33 Rozenblum E, Schutte M, Goggins $M$, et al. Tumor-suppressive pathways in pancreatic carcinoma. Cancer Res 1997;57:1731-4.

34 Terhune PG, Phifer DM, Tosteson TD, et al. K-ras mutation in focal proliferative lesions of human pancreas. Cancer Epidemiol Biomarkers Prev 1998:7:515-21.

35 Lüttges J, Reinecke-Lüthge A, Möllmann B, et al. Duct changes and k-ras mutations in the disease-free pancreas: analysis of type, age relation and spatial distribution. Virchows Arch 1999;435:37-45.

36 Malats N, Porta M, Corominas JM, et al. Ki-ras mutations in exocrine pancreatic cancer: association with clinico-pathological characteristics and with tobacco and alcohol consumption. Int J Cancer 1997;70:661-7.

37 Berger DH, Chang H, Wood M, et al. Mutational activation of K-ras in nonneoplastic exocrine pancreatic lesions in relation to cigarette smoking status. Cancer 1999:85:326-32.

38 Porta M, Malats N, Guarner L, et al. Association between coffee drinking and $\mathrm{K}$-ras mutations in exocrine pancreatic cancer. J Epidemiol Community Health 1999;53:702-9.

\section{EDITOR'S QUIZ: GI SNAPSHOT}

\section{Answer}

From question on page 478

At laparotomy, a massive mesenteric cyst was found and fully excised. It contained $900 \mathrm{ml}$ of creamy fluid and three calculi. Surprisingly, pathology demonstrated an inflammatory cyst arising from within the omentum, lined by granulation tissue, and the largest calculus had the microscopic appearance of a gall stone. There was no evidence of malignant cells in the specimen. The patient fully recovered from surgery and remains without evidence of recurrence of malignancy.

This remarkable finding conceivably relates to perforation of the cystic duct by a gall stone which had resided within the omentum for more than 10 years and formed the massive mesenteric cyst.

doi: 10.1136/gut.2004.051342 